\title{
Mechanical and Thermal Properties of Basalt Fibre Reinforced Polymer Lamellas for Renovation of Concrete Structures
}

\author{
Szymon Grzesiak ${ }^{1}$, Matthias Pahn ${ }^{1, *}$, Andreas Klingler ${ }^{2}{ }^{-0}$, Emmanuel Isaac Akpan ${ }^{2}{ }^{-}$, \\ Milan Schultz-Cornelius ${ }^{1}$ and Bernd Wetzel ${ }^{2}$ \\ 1 Department of Civil Engineering, Technical University of Kaiserslautern, 67663 Kaiserslautern, Germany; \\ szymon.grzesiak@bauing.uni-kl.de (S.G.); milan.schultz-cornelius@bauing.uni-kl.de (M.S.-C.) \\ 2 Leibniz-Institut für Verbundwerkstoffe GmbH (IVW), Erwin-Schrödinger-Straße 58, \\ 67663 Kaiserslautern, Germany; andreas.klingler@ivw.uni-kl.de (A.K.); \\ emmanuel.akpan@ivw.uni-kl.de (E.I.A.); bernd.wetzel@ivw.uni-kl.de (B.W.) \\ * Correspondence: matthias.pahn@bauing.uni-kl.de
}

check for

updates

Citation: Grzesiak, S.; Pahn, M.;

Klingler, A.; Akpan, E.I.;

Schultz-Cornelius, M.; Wetzel, B.

Mechanical and Thermal Properties

of Basalt Fibre Reinforced Polymer

Lamellas for Renovation of Concrete

Structures. Polymers 2022, 14, 790.

https://doi.org/10.3390/

polym 14040790

Academic Editor: Libo Yan

Received: 15 December 2021

Accepted: 14 February 2022

Published: 18 February 2022

Publisher's Note: MDPI stays neutral with regard to jurisdictional claims in published maps and institutional affiliations.

Copyright: (C) 2022 by the authors. Licensee MDPI, Basel, Switzerland. This article is an open access article distributed under the terms and conditions of the Creative Commons Attribution (CC BY) license (https:// creativecommons.org/licenses/by/ $4.0 /)$.

\begin{abstract}
The level of energy consumption in renovation activities of buildings has huge advantages over the demolition of old buildings and the construction of new structures. Such renovation activities are usually associated with the simultaneous strengthening of their elements, such as externally bonded carbon fibre reinforced polymer (CFRP) lamellas or sheets on vertical and horizontal surfaces as structural reinforcements. This means the process of refurbishing a building, as well as the raw materials themselves have a significant impact on $\mathrm{CO}_{2}$ emissions and energy consumption. This research paper demonstrates possibilities of replacing state of the art, highly energy-intensive CFRP lamellas with basalt fibre reinforced plastics as energy-efficient structural reinforcements for building constructions. The mechanical and thermal properties of basalt fibre reinforced polymer (BFRP) composites with variable matrix formulations are investigated. The article considers macroand microstructures of innovative BFRP. The investigations focus on fibre-matrix interactions with different sizing formulations and their effect on the tensile strength, strain as well as modulus of elasticity.
\end{abstract}

Keywords: basalt fibre reinforced polymer; reinforced concrete; strengthening

\section{Introduction}

The renovation rate of existing buildings exceeds the construction of new buildings and has been increasing constantly in the last years [1]. The use of renovations as opposed to new constructions have recently been implemented in industrial, residential and commercial buildings [2]. This will likely increase in the future as the society gains awareness of the advantages of renovation over new constructions [3]. The most popular way to strengthen the tension zone in reinforced concrete (RC) elements is to use layers of concrete reinforced with textile- and fibre-reinforced polymers (FRP) like lamellae, sheet [4] or rebar [5]. These externally bonded (ED) reinforcements are already successfully applied to strengthen existing buildings. In concrete repair, the FRP retrofit or lamellae are usually attached to the surface of the concrete using reactive adhesives. Installation can also be done by placing the lamellae a small distance into the surface of the concrete [6]. Established for decades, reinforcing materials made of carbon-fibre-reinforced plastics have satisfying mechanical properties. However, carbon fibres have high amounts of embodied energy (total energy intensity of carbon fibre is estimated to be $284 \mathrm{MJ} / \mathrm{kg}$ [7-9]) and are generally expensive. On the other hand, basalt fibres are sustainable materials with comparatively lower amount of embodied energy (total energy intensity of basalt fibre of $18 \mathrm{MJ} / \mathrm{kg}$ [10-12]. Replacing carbon with basalt fibres in FRP for concrete renovation will increase environmental sustainability. The manufacturing cost of basalt fibres are also 
lower than carbon fibres. Their application in the manufacturing of lamella for strengthening of RC structures will have cost and environmental advantages over carbon fibre lamella [13]. A good understanding of the mechanical properties of BFRP lamellae will enable a cost-effective and sustainable design of new retrofitting techniques in building constructions.

A few studies have reported the mechanical properties of basalt-fibre-reinforced composites [14]. Some studies focused on the mechanical properties of BFRP bars [15,16]. Nonetheless, a few studies investigated the mechanical properties of BFRP laminates [17]. Chen et al. [18] examined the mechanical properties of BFRP under quasistatic and dynamic loading conditions. Tensile strength, modulus of elasticity and failure strain were 1642.2 $\mathrm{MPa}, 77.9 \mathrm{GPa}$ and 0.021 respectively. Hashim et al. [19] examined the effect of matrix modification with silica particles on the tensile behaviour of BFRP composites under static conditions. Results showed a positive influence of silica particles on the BFRP mechanical properties. The particles increased the tensile strength of the composite product, for example, addition of $25 \mathrm{wt} . \%$ of silica particles increased the tensile strength from $400 \mathrm{MPa}$ to $640 \mathrm{MPa}$. They enhanced the fibre-matrix interphase bonding. Azimpour-Shishevan et al. [20] investigated the effect of thermal cycling on properties of BFRP composites. Samples were subjected to temperature cycles (the cycle goes from room temperature to $+120{ }^{\circ} \mathrm{C}$, then from $+120{ }^{\circ} \mathrm{C}$ to $-40{ }^{\circ} \mathrm{C}$ and finally from $-40{ }^{\circ} \mathrm{C}$ to room temperature) for a specified number of times and the mechanical properties were examined. Results showed that the tensile strength, modulus and inter laminar shear stress of the BFRP increased with increasing number of cycles until 80 cycles but decreased with further increase. The initial increase in properties was attributed to the effect of postcuring. $\mathrm{Hu}$ et al. [21] studied the shear modulus of BFRP laminates at different temperatures. Results showed that increase in temperature resulted to a degradation in mechanical performances due to degradation of the epoxy resin matrix. Lu and Xian [22] studied the combined effects of sustained tensile loading and elevated temperatures on the mechanical properties of a pultruded BFRP plates. It was observed that the temperatures affected tensile strength and modulus. For example, at $80{ }^{\circ} \mathrm{C}$ the tensile strength decreased by $9.8 \%$ and tensile modulus by $1.9 \%$. The higher the exposure temperature the greater the resulting degradation. To improve the mechanical properties of BFRP composites, Matykiewicz et al. [23] studied the effect of different matrix modifications on the properties of basalt-fibre-epoxy composites. The BFRP were modified with zeolite or silsesquioxane particles and the mechanical properties determined under static conditions. The addition of particles decreased the tensile strength from $300 \mathrm{MPa}$ to $270 \mathrm{MPa}$ and the elastic modulus from $85 \mathrm{GPa}$ to $66 \mathrm{GPa}$. $\mathrm{Li}$ et al. [24] examined the strain rate effects on tensile strength, Young's modulus, and failure strain of BFRP under quasistatic and dynamic loadings. It was observed that the type of resin did not influence the tensile properties of BFRP composites, because the strength of epoxy resin is very small as compared to that of the fibre.

The aim of this work is to investigate the effect of different matrix formulations and fibre sizing on the mechanical properties of basalt fibre reinforced polymer composites. Furthermore, the addition of core-shell rubber (CSR) particles has been tested in the matrix formulation. The CSR nanoparticles are expected to reduce or slow down the damage progression.

\section{Methodology}

\subsection{Materials}

The basalt fibre rovings in the study had a linear density of 2400 Tex (gram per kilometre), and an average diameter of $13 \mu \mathrm{m}$. The basalt fibres were obtained from Deutsche Basalt Fibre (DBF) GmbH, Frankfurt am Main, Germany. The basalt fibres were supplied with a single and double silane-based sized layer. As resins Biresin CR141 and CR144, as well as the hardener CH141 and the accelerator CA141 were obtained from Sika Deutschland GmbH [25]. CH141 and CA141 were used as curatives for CR141, Aradur CH917 (hardener) and DY070 (accelerator) were obtained from Huntsman Corporation 
and served as curatives for the second resin system. The curatives are chemically the same yet supplied by different companies. Core-shell rubber (Polybutadiene) nanoparticles (KaneAce MX153 [26]) were supplied by Kaneka Belgium N.V. as a master batch. The master batch contains $33 \mathrm{wt}$ \% of core-shell rubber particles with a diameter of approximately 50-100 nm, being homogeneously dispersed in a diglycidyl ether of a bisphenol A-based epoxy resin system.

\subsection{Manufacturing of BFRP-Lamellae}

Basalt fibre lamella (BFL) were pultruded using the pultrusion line of the CG-TEC $\mathrm{GmbH}$, Spalt, Germany (cf. Table 1). Two resin formulations were used for the pultrusion process: A-containing CR144, CH917 and DY070 and B-containing CR141, CH141 and CA141, each mixed in stoichiometric proportions. For some samples, the resins were modified with $5 \mathrm{wt}$ \% core-shell rubber particles. The processability of MX153 was found to be challenging. Heating the modified resin system to higher temperatures to decrease the viscosity for processing was found to reduce its pot life.

Table 1. Sample designations.

\begin{tabular}{ccccc}
\hline No & Description & Fibre Sizing & $\begin{array}{c}\text { Matrix } \\
\text { Modification }\end{array}$ & $\begin{array}{c}\text { Resin } \\
\text { Formulation }\end{array}$ \\
\hline 1 & A1S & Once & Non & $\mathrm{A}$ \\
2 & A2S & Twice & Non & $\mathrm{A}$ \\
3 & Amod1S & Once & $5 \mathrm{wt.} \%$ & $\mathrm{~A}$ \\
4 & Amod2S & Twice & $5 \mathrm{wt} \%$ & $\mathrm{~A}$ \\
5 & Bmod1S & Once & $5 \mathrm{wt.} \%$ & $\mathrm{~B}$ \\
6 & Bmod2S & Twice & $5 \mathrm{wt} \%$ & $\mathrm{~B}$ \\
\hline
\end{tabular}

In the pultrusion process, fibres were rolled out from the roving into the production line through a guided plate. The number of rovings for the selected batch was between 69 and 72. Each roving consisted of 6000 fibres. Due to the application of different sizing strategies, i.e., sized once vs. sized twice, the effective fibre diameter changed. The fibres then went through the resin impregnation bath at a speed of $6 \mathrm{~mm} / \mathrm{s}$. The impregnated fibres further passed through a preformer (cross-section $32 \mathrm{~mm} \times 3 \mathrm{~mm}$ in Figure 1) to the curing chamber. The $1 \mathrm{~m}$-long chamber was divided into three equal compartments operating at temperatures of $120{ }^{\circ} \mathrm{C}, 130{ }^{\circ} \mathrm{C}$ and $165^{\circ} \mathrm{C}$, respectively. The pulling force, which was transmitted to the BFRP-profile by a caterpillar pulling machine, was equal $2.2 \mathrm{kN}$.
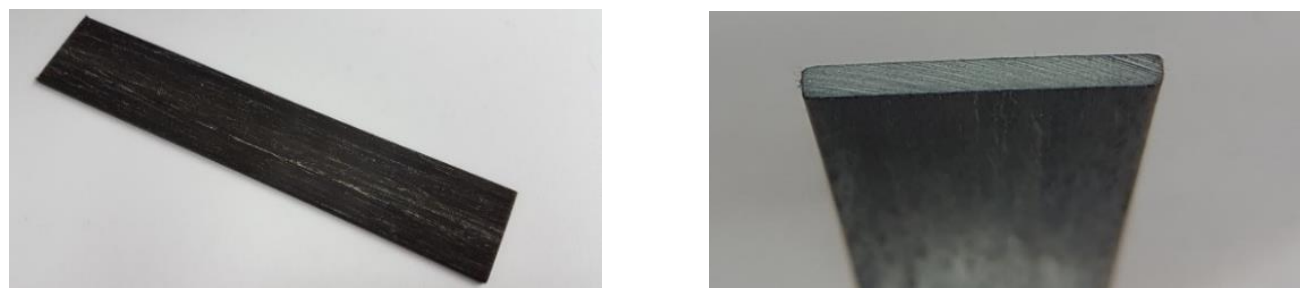

Figure 1. Profile pattern of BFL with cross-section $32 \mathrm{~mm} \times 3 \mathrm{~mm}$.

\subsection{Charaterization}

\subsubsection{Fibre Volume Fraction}

The fibre volume fraction of the pultruded lamella was determined via grey-scale analyses of light microscopy images [27]. Samples were embedded in an epoxy resin then grounded and polished using an automatic grinding machine. Grinding was performed with water with sequential change in emery papers from P400 to P4000 grit. The grounded samples were subsequently polished with a diamond solution of 3 and $1 \mu \mathrm{m}$. Fibre volume 
content and porosity of the samples were analysed using a Leica light microscope equipped with a grey scale analysis software.

\subsubsection{Tensile Test}

Tensile tests were conducted of the basalt fibre lamella according to EN 2561 standard [28] using a testing machine (Schenck Hydropuls, Darmstadt, Germany) with a load cell of $250 \mathrm{kN}$ [29]. Samples with a dimension of $250 \mathrm{~mm} \times 15 \mathrm{~mm} \times 3 \mathrm{~mm}$ [30] were conditioned in a humidity chamber at a temperature of $20^{\circ} \mathrm{C}$ and a relative humidity of $60 \%$ for $48 \mathrm{~h}$ [31]. The samples were loaded in the fibre direction at a constant speed of $2 \mathrm{~mm} / \mathrm{min}$ until failure (see Figure 2). Strain measurements were conducted using an extensometer, attached to the samples. To ensure repeatability, five specimens were tested for each sample. The tensile strength was calculated using Equation (1). Where: $P_{\max }$ is the maximum load, dimensions $b$ and $h$ are the width and thickness of the samples, respectively. The features are measured with an electronic caliper at the beginning of the tests.

$$
\sigma_{t}=\frac{P_{\max }}{b \cdot h}
$$

(1)

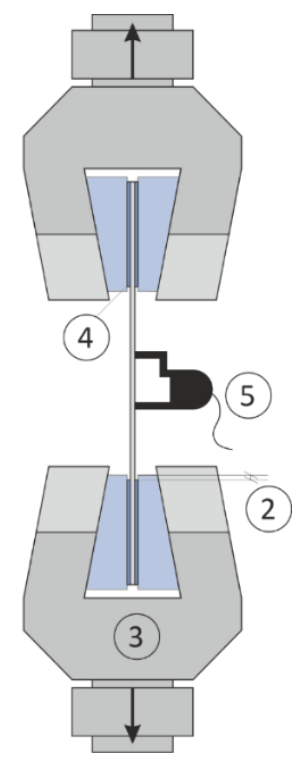

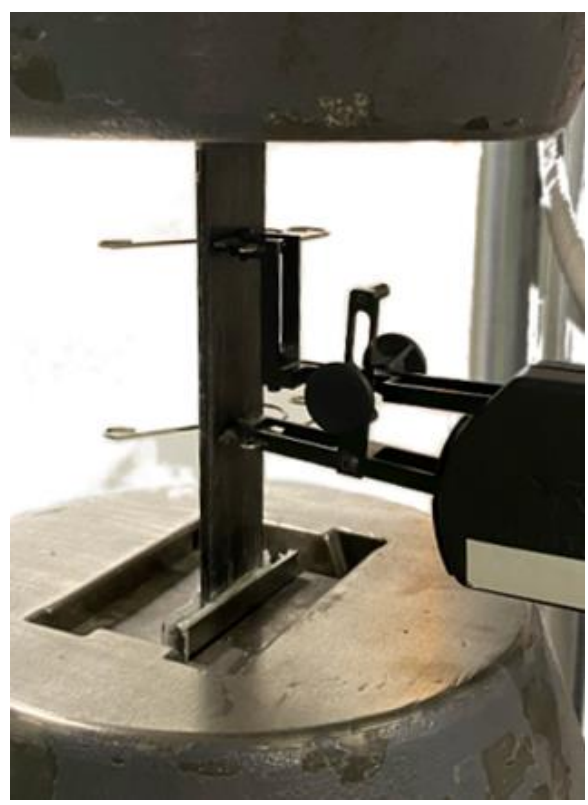

Figure 2. Schematic of tensile test: $1=$ free length, $2=$ projection of jaws, $3=$ jaws, $4=$ glued end tabs made from unidirectional glass-epoxy laminate, $5=$ extensometer.

Modulus of elasticity was calculated according to EN 2561 [28] using Equation (2). Where: $\varepsilon_{A}$ and $\varepsilon_{B}$ are the strain parallel to the fibre direction corresponding to $0.1 \cdot P_{\max }$ and $0.5 \cdot P_{\text {max }}$, respectively.

$$
E_{11}=\frac{0.4 \cdot P_{\max }}{b \cdot h \cdot\left[\varepsilon_{B}-\varepsilon_{A}\right]}
$$

\subsubsection{Thermomechanical Analysis}

The viscoelastic properties of the different lamellae were investigated by dynamic mechanical analysis (DMA, Q800, TA Instruments, Heidrun Klement, Germany) in a double cantilever setup at a frequency of $f=10 \mathrm{~Hz}$. The rectangular specimens of $30 \mathrm{~mm} \times 5 \mathrm{~mm}$ $\times$ and $2 \mathrm{~mm}$ were loaded perpendicular to the fibre direction. The temperature was varied from $-100{ }^{\circ} \mathrm{C}$ up to $250{ }^{\circ} \mathrm{C}$ at a heating rate of $2{ }^{\circ} \mathrm{C} / \mathrm{min}$. The glass transition temperature was determined as the peak value of the mechanical damping $(\tan \delta)$ [32]. 


\subsubsection{SEM Analysis}

Structural analyses were performed using a scanning electron microscope (Zeiss Supra 40VP, Oberkochen, Germany) at various magnifications, deploying a secondary electron detector. The accelerating voltage was $5 \mathrm{kV}$. Surfaces to be examined were sputtered with a gold-palladium layer at $I=40 \mathrm{~mA}$ for $80 \mathrm{~s}$ (Balzers Sputter Coater SCD050, Balzers, Liechtenstein).

\section{Results and Discussion}

\subsection{Fibre Volume Fraction}

The fibre content has an impact not only on the cross-linking process of the resin system [33] but also, as a result, on mechanical properties, such as the elastic modulus and the tensile strength. Fiore et al. [34] summarised the influence of different fibre contents in $\mathrm{BF}$ composites on the various properties. As has been noted by Amuthakkannan et al. [35], the higher the BF content is, the higher is the tensile strength. Therefore, to quantify the fibre volume content of the BFRP lamella, corresponding samples are extracted from the lamella and embedded in a resin. The specimens have then been polished, and the fibre volume content was calculated using greyscale analysis based on light microscopy images (see Figure 3). Fibre volume fraction and porosity of the developed BFL are shown in Table 2.

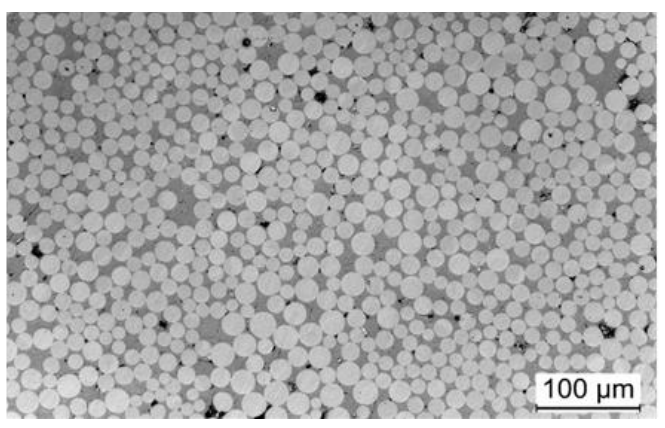

(a)

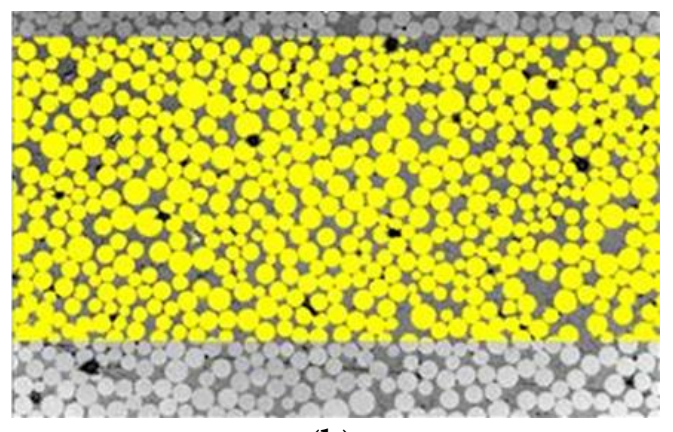

(b)

Figure 3. Determination of the fibre volume content of the developed BFL: (a) light microscopy image, (b) grey scale analysis.

Table 2. Fibre volume fraction and porosity of the developed BFL.

\begin{tabular}{cccc}
\hline No & Description & Fibre Content (\%) & Pore Content (\%) \\
\hline 1 & A1S & $69.0 \pm 0.8$ & $1.30 \pm 0.20$ \\
2 & A2S & $69.8 \pm 0.5$ & $0.98 \pm 0.07$ \\
3 & Amod1S & $65.3 \pm 1.5$ & $1.40 \pm 0.20$ \\
4 & Amod2S & $59.2 \pm 0.9$ & $1.20 \pm 0.30$ \\
5 & Bmod1S & $68.4 \pm 1.0$ & $1.10 \pm 0.10$ \\
6 & Bmod2S & $62.2 \pm 1.9$ & $1.20 \pm 0.30$ \\
\hline
\end{tabular}

The BFL show a fibre volume content of approx. 60 to $70 \mathrm{vol} \%$. The unmodified and double sized system (A2S) shows the highest fibre volume content. Modification with MX153 slightly reduces $\mathrm{v}_{\mathrm{f}}$ (sample Amod1s). In the lamella with double sized fibres and core-shell rubber particles, there is a further reduction in the fibre volume content (Amod2s).

Another parameter to be considered is the pore concentration in fibre reinforced composites. The BFL show a pore content of approx. 1.0 to 1.4 vol.\%. Pores and inhomogeneities have an extremely detrimental effect on the stiffness of a material. Pores can be introduced into the materials during production process or reduced by the addition of inert or active filler materials [36]. The high impregnation quality leads to a ductile 
material, fracture-resistant and stiffness of matrix. The pore content negatively affects the durability of the manufactured BFL. Particular attention should be given to prevent bevor crack development in the discontinuity of the material's microstructure in corrosive media.

\subsection{Tensile Properties}

Figure 4a depicts a representative stress-strain behaviour of a basalt fibre lamella. The figure shows that the lamella fails in a brittle manner, which is in line with a previous study on the static mechanical behaviour of woven basalt fibre reinforced epoxy composites [37,38]. As evidenced in Figure 4a the composites fail primarily by fibre breakage and debonding from the matrix.

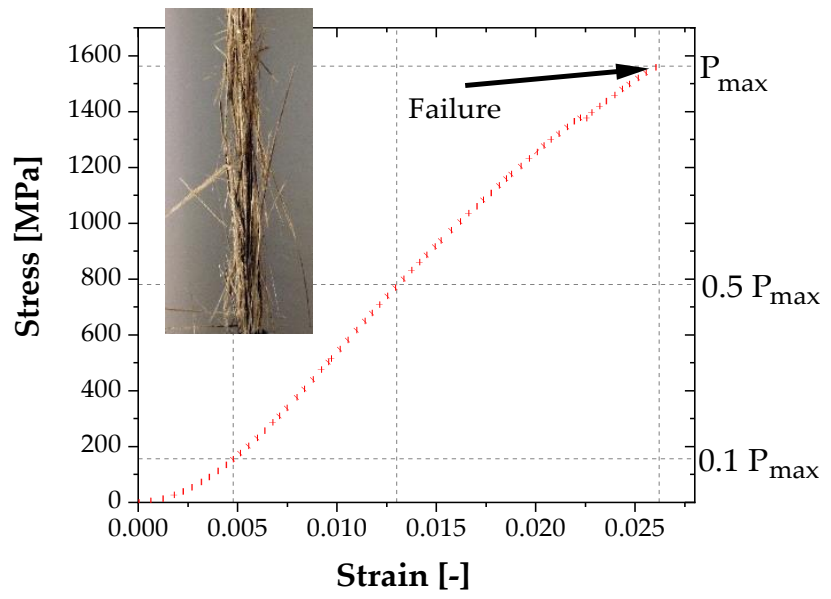

(a)

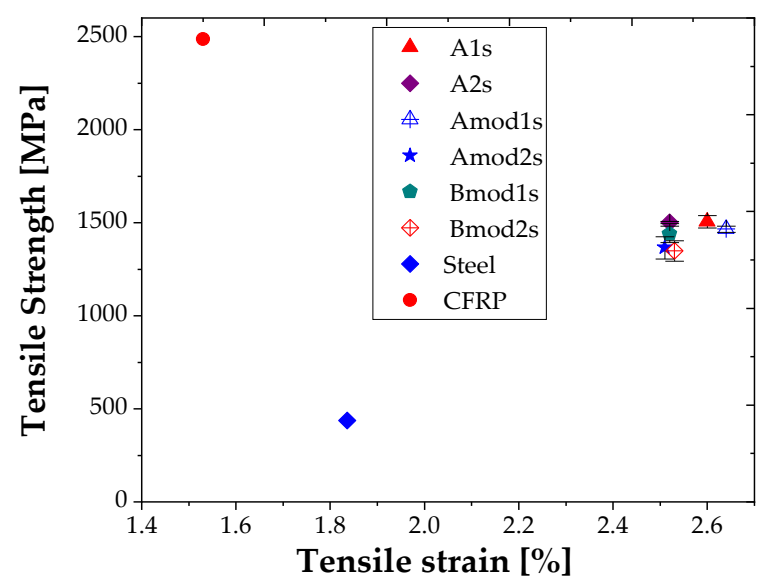

(c)

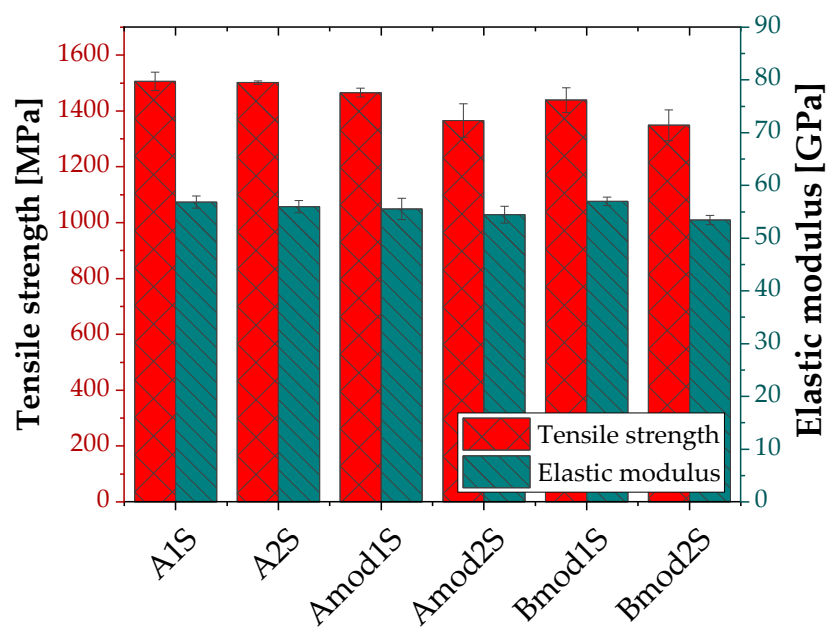

(b)

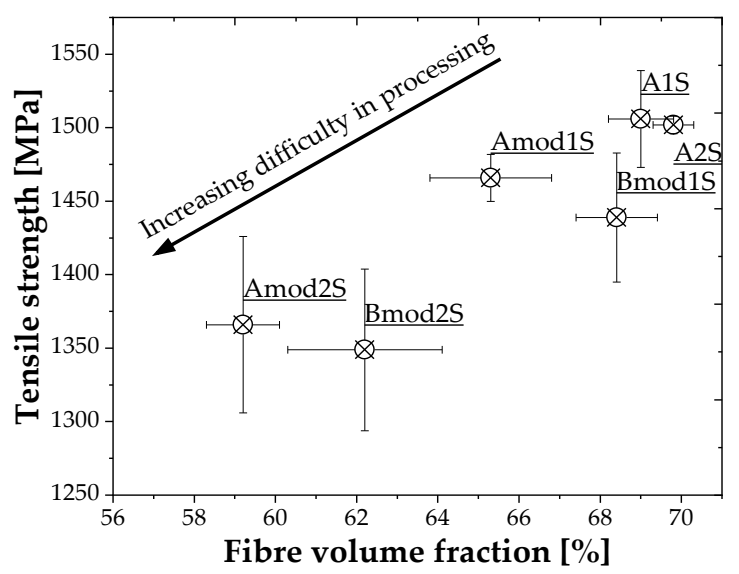

(d)

Figure 4. Tensile behaviour of the developed basalt fibre lamella: (a) typical stress strain curve of the $\mathrm{BFL}$ and fracture mode of the BFL, (b) effect of treatments on tensile strength and modulus of the BFL, (c) comparative tensile strength of BFL, CFRP and steel [39], (d) synergistic effect of nanoparticle modification and sizing on the tensile performance of the BFL.

Figure $4 \mathrm{~b}$ shows the variation of tensile strength and modulus of the developed basalt fibre lamella with respect to the applied sizing (1S and 2S, cf. Section 2.1) and matrix modification (mod). It is evident from the figure that the matrix modification led to a slight decrease in tensile strength. The elastic modulus shows almost no significant difference between the treatments. Composites with one-time sized fibre and no matrix modification 
show the highest tensile strength (1562 MPa) followed by the composite with double sizing and no matrix modification.

For orientation, Figure 4c compares the tensile strength of commercial steel [39] and carbon fibre lamella with the newly developed basalt fibre lamellae. The tensile strain of BFL is in the range of $2.5 \%$ and $2.7 \%$. The basalt fibre lamella surpasses steel but not the carbon fibre lamella in tensile performance. However, the strain at maximum load of BFL is superior to the strain at maximum load of CFRP based lamellae.

Figure $4 \mathrm{~d}$ illustrates the synergistic effect of the nanoparticle matrices and the fibre sizing on the tensile strength. BFLs with double sized fibres and matrix modification show lower tensile strengths, which can be attributed to a reduced fibre volume fraction $\mathrm{v}_{\mathrm{f}}$. The fibre volume fraction decreases since the number of rovings in processing for the selected batch also decrease. This is due to the different fibre diameters with single and double sizing, which could be passed through a preformer to the curing chamber. Double sizing and matrix modification synergistically influence the difficulty of pultrusion of the BFL. On the other hand, composites with single sizing and nanoparticle modification show a moderate fibre volume fraction and consequently moderate tensile strength. It is postulated that the synergistic effect becomes lower when single sized fibres are used resulting in ease of processing and consequently an elevated fibre volume fraction is obtained. Composites without matrix modification show the highest fibre volume fraction and consequently higher tensile strength. Here, it is deduced that the driving force for the stated synergistic effect is the increase in viscosity of the resin as a result of addition of the nanoparticles (see Figure 5). However, this effect becomes stronger when the thickness of the sizing is increased.

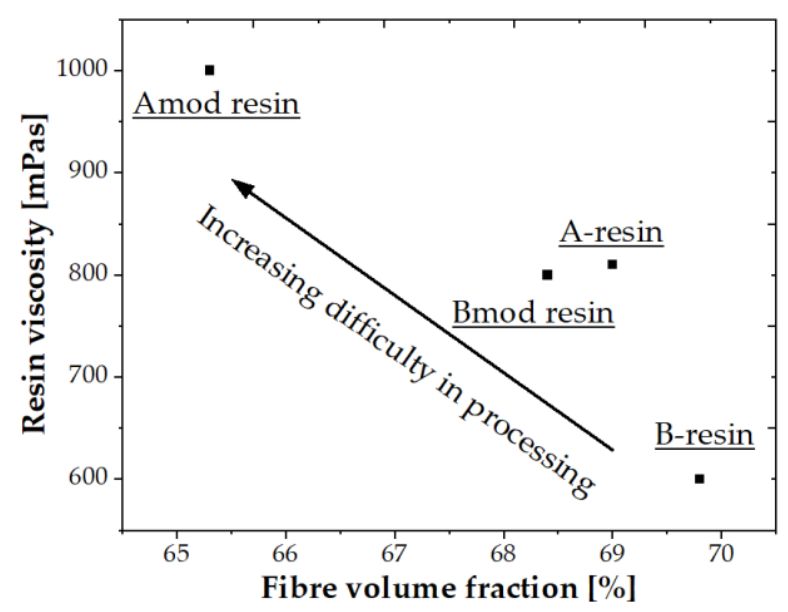

Figure 5. Correlating resin viscosity and fibre volume fraction of BFL.

\subsection{Thermomechanical Properties}

To investigate the influence of the modifiers and the applied fibre sizing on the thermomechanical properties of the cured BFRP lamellae, dynamic mechanical analyses were performed. Figure 6a shows the temperature dependent development of the mechanical damping coefficient $\tan \delta$ of the various basalt fibre systems. All BFLs show a quite similar dynamic-mechanical behaviour, i.e., the damping increases slowly with increasing temperature up to the region of the dynamic glass transition, i.e., the transition from the solid to the viscoelastic state. This is also reflected in a sharp drop of the storage modulus (Figure $6 \mathrm{~b}$ ). The data show dynamic glass transition temperatures $\mathrm{T}_{\mathrm{g}}$ in the range from $125.6^{\circ} \mathrm{C}$ to about $135^{\circ} \mathrm{C}$, whereas the CR141 systems (B) show the highest values. The mechanical damping is strongly dependent on the present fibre volume content of the samples and varies in the range from 0.356 and 0.432 . The basalt fibre has an approximately five times lower thermal conductivity $(0.031-0.038 \mathrm{~W} / \mathrm{mK}$ [40-42]) compared to the epoxy resin system (0.1 to $0.2 \mathrm{~W} / \mathrm{mK}[43,44])$, which can influence the heating process (heat flux) of the sample and thus the relaxation behaviour. The values are summarised in Table 3. 
There was no discernible postcuring of the systems, which would have been indicated by an increasing modulus after passing the region of the glass transition.

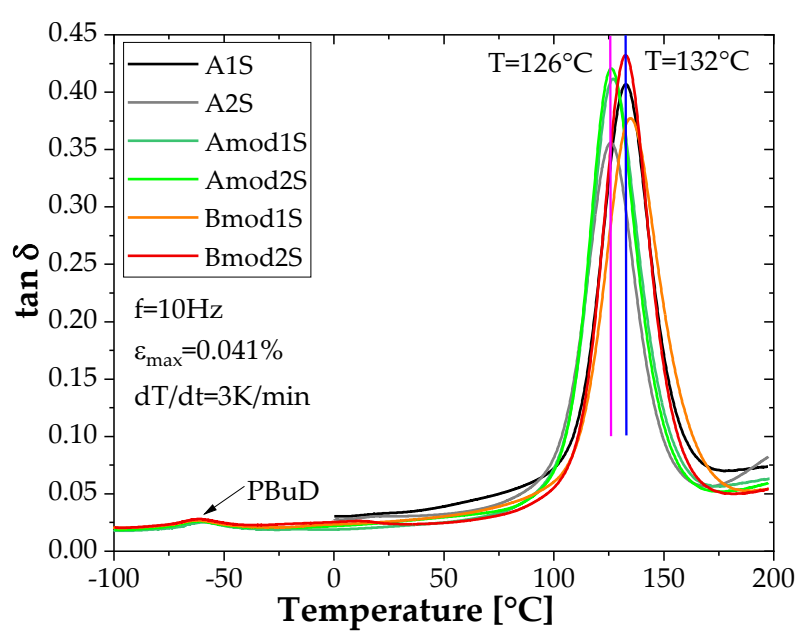

(a)

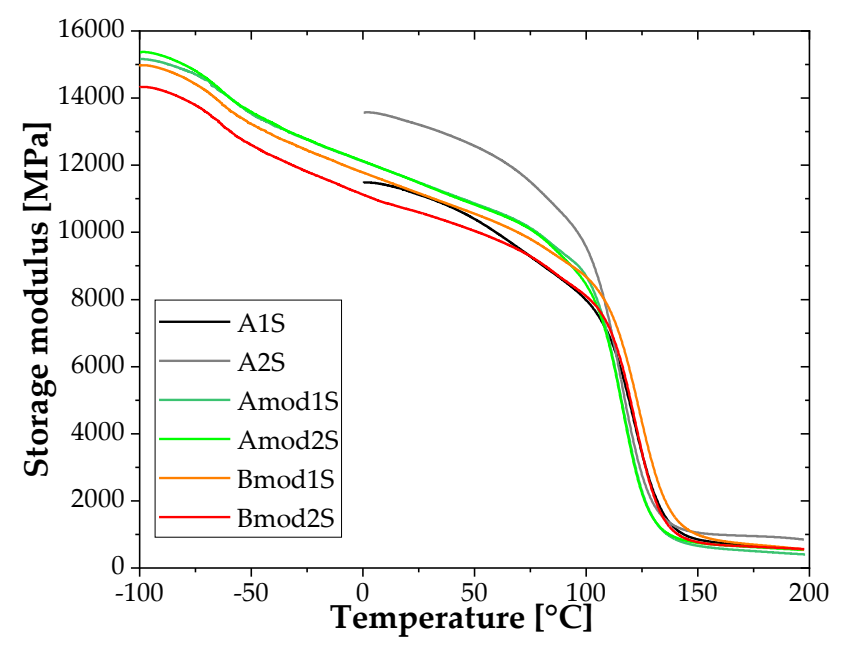

(b)

Figure 6. Temperature-dependent materials' behaviour: (a) mechanical damping $\tan \delta$, (b) storage modulus.

Table 3. Thermomechanical properties of the developed BFL.

\begin{tabular}{lccc}
\hline No & Description & Glass Transition Temperature $\left[{ }^{\circ} \mathbf{C}\right]$ & Mechanical Damping Tan $\delta$ \\
\hline 1 & A1S & 132.8 & 0.407 \\
2 & A2S & 125.6 & 0.356 \\
3 & Amod1S & 126.8 & 0.412 \\
4 & Amod2S & 126.1 & 0.421 \\
5 & Bmod1S & 135.0 & 0.377 \\
6 & Bmod2S & 132.8 & 0.432 \\
\hline
\end{tabular}

Conclusively, it seems as if neither the fibre sizing (strategy) nor the matrix modification have an effect on the thermomechanical behaviour of such lamella, at least in the investigated temperature range.

\subsection{SEM Analyses}

Figure 7 shows representative interlaminar fracture surfaces of the different basalt fibre reinforced lamella, obtained via scanning electron microscope (SEM) [45]. Qualitatively, there are only minor differences between the various fracture surfaces of the different material systems. However, the adhesion quality of the double-sized fibres seems visually better than the fibre-matrix interaction of the single-sized systems, especially Figure $7 \mathrm{~b}, \mathrm{f}$ show an enhanced fibre-matrix adhesion. The more sizing is present on the fibres the better the bonding quality to the matrix system. Even though, this enhanced interaction quality did not show a significant improvement of the tensile properties, as shown in Figure $4 b$, it is expected to yield a higher resistance to interlaminar crack propagation, i.e., enhanced fracture resistance of the lamella. 


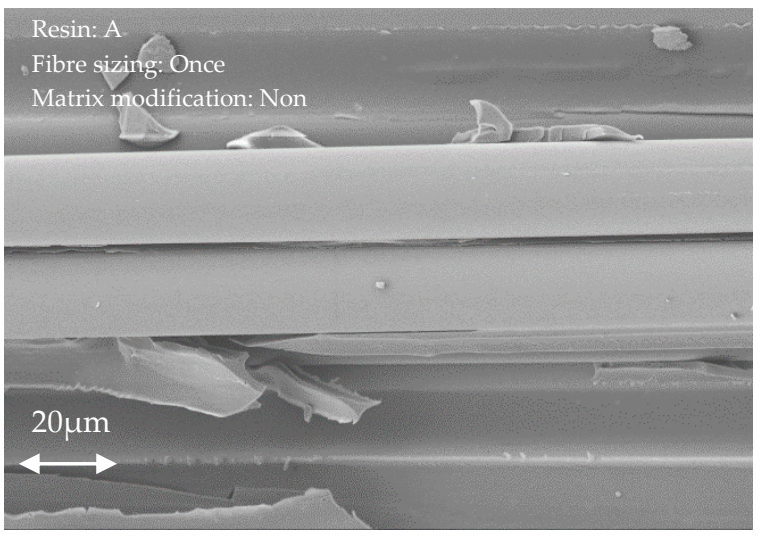

(a)

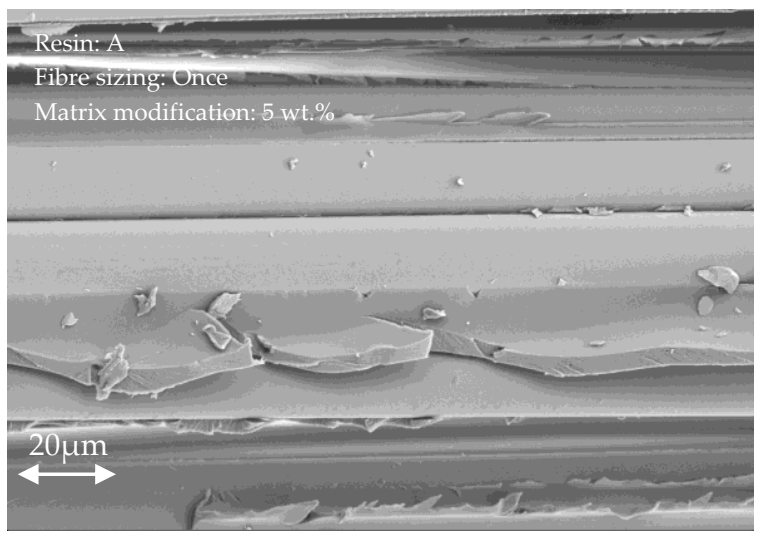

(c)

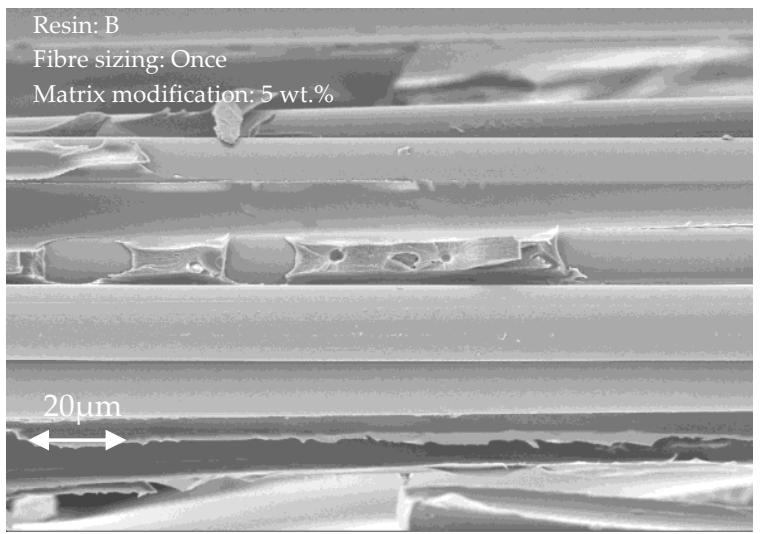

(e)

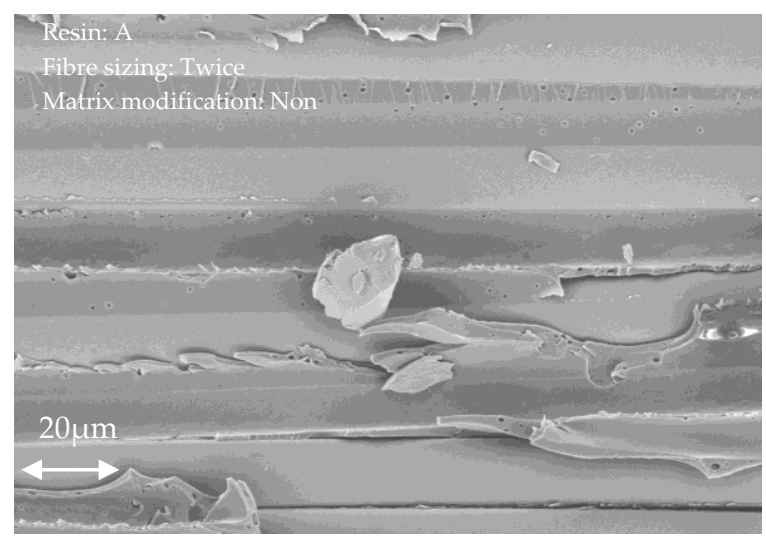

(b)

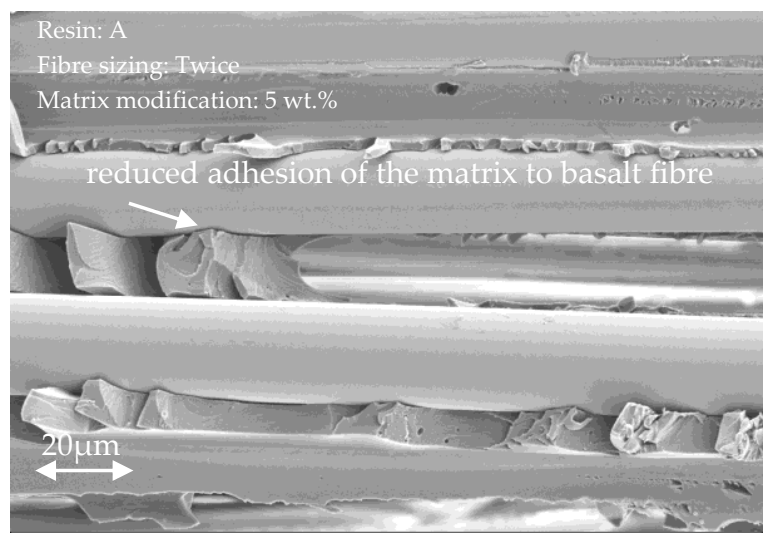

(d)

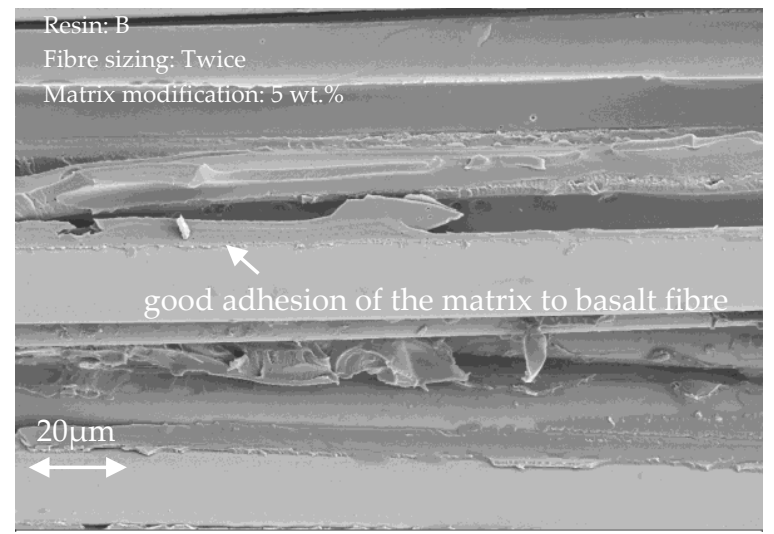

(f)

Figure 7. SEM analyses of the developed basalt fibre lamella: (a) A1S, (b) A2S, (c) Amod1s, (d) Amod2s, (e) Bmod1s, and (f) Bmod2s.

\section{Conclusions}

This paper presented a study on the mechanical properties of BFRP lamellae modified with core-shell rubber nanoparticles under the influence of a single and double sizing strategy. The goal was to investigate the influence of a matrix modification, while, simultaneously improving the fibre matrix interface properties, on the mechanical properties of basalt fibre reinforced polymer composites. The following conclusions can be drawn from this study: 
- Basalt fibre reinforced polymer lamellae were successfully prepared in a pultrusion process.

- Tensile tests show the brittle character of BFRP composites. Quasistatic failure occurs immediately after leaving the linear-elastic region of the stress-strain curve.

- The type of fibre sizing strategy (sized once vs. sized twice) affects the effective fibre volume of the BFRP lamellae. This is because the cross-section of the lamella, defined by the tooling, is always the same and thus, the number of fibres pultrude through the cross-section needs to be reduced if the fibre diameter increases. Hence, if more silane sizing is used, the apparent fibre diameter increases. This effect is superimposed by an increased resin viscosity in the case of a CSR nanoparticle modified resin. Accordingly, the tensile strength and Young's modulus decrease, once $v_{f}$ is reduced.

- The more sizing is applied on the basalt fibres, the higher the adhesion between fibre and matrix in the BFRP. This positive aspect has not been reflected in the mechanical properties of the composites because more sizing is related to the lower fibre volume fraction. Subsequently, this causes the mechanical properties to decrease.

- The type of epoxy resin influences the properties of BFRP lamellae. The sample with resin $\mathrm{A}$, which had higher tensile strength than the sample with resin $\mathrm{B}$, shows a similar trend in mechanical properties of the pultruded polymer. Furthermore, the addition of the core-shell rubber particles changes the properties of the matrix.

- Dynamic mechanical analyses showed that the resin modification does not affect the (thermo-)mechanical properties of the BFL. Furthermore, the sizing does not alter the dynamic glass transition.

Future investigations will focus on materials having the same fibre volume concentration, to better assess the effect of matrix and sizing modifications. The higher load capacity of strips with different diameter of fibre located in one pultruded cross-section is expected. Investigations on bond behaviour on the concrete for a whole retrofitting system with new basalt fibre strips are required.

Other studies should focus on the thermal durability [46] and corrosion resistance of BFRP with an example of the methodology procedure shown in $[47,48]$. The safety life cycle of BFRP strips should be examined in fatigue tests. Also of importance is the adhesion of BFRP lamellae to the concrete, which should be tested.

Author Contributions: Conceptualization, S.G., A.K., E.I.A., M.S.-C., B.W. and M.P.; methodology, S.G., A.K., E.I.A. and M.S.-C.; investigation, S.G., A.K. and E.I.A.; writing-original draft preparation, S.G., A.K. and E.I.A.; writing-review and editing, S.G., A.K., E.I.A., M.S.-C., B.W. and M.P.; supervision, B.W. and M.P.; project administration, S.G. and M.S.-C.; funding acquisition, M.S.-C., B.W. and M.P. All authors have read and agreed to the published version of the manuscript.

Funding: This research work was supported by the Federal Ministry for Economic Affairs and Energy in Germany (BMWi-Bundesministerium für Wirtschaft und Energie) under grant 03ET1653A.

Data Availability Statement: Not applicable.

Acknowledgments: The authors would like to thank the staff of the Civil Engineering Department of Technical University in Kaiserslautern and Leibniz-Institut für Verbundwerkstoffe GmbH (IVW) for their support extended during the experimental works carried out in the laboratory.

Conflicts of Interest: The authors declare no conflict of interest.

\section{References}

1. Gornig, M.; Michelsen, C.; Bruns, M. Bauwirtschaft weiter im Vorwärtsgang-Staatliche Impulse treiben die Preise. DIW Wochenber. 2019, 86, 3-14.

2. European Commission. Comprehensive Study of Building Energy Renovation Activities and the Uptake of Nearly Zero-Energy Buildings in the EU Final Report; Publications Office of the European Union: Gent, Belgium, 2019.

3. Filippidou, F.; Nieboer, N.; Visscher, H. Are we moving fast enough? The energy renovation rate of the Dutch non-profit housing using the national energy labelling database. Eng. Policy 2017, 109, 488-498. [CrossRef]

4. Martinola, G.; Meda, A.; Plizzari, G.A.; Rinaldi, Z. Strengthening and repair of RC beams with fiber reinforced concrete. Cem. Concr. Compos. 2010, 32, 731-739. [CrossRef] 
5. Gopinath, S.; Murthy, A.R.; Patrawala, H. Near surface mounted strengthening of RC beams using basalt fiber reinforced polymer bars. Constr. Build. Mater. 2016, 111, 1-8. [CrossRef]

6. Seo, S.; Choi, K.; Kwon, Y.; Lee, K. Flexural strength of RC beam strengthened by partially de-bonded near surface-mounted FRP strip. Int. J. Concr. Struct. Mater. 2016, 10, 149-161. [CrossRef]

7. Suzuki, T.; Jun, T. Prediction of energy intensity of carbon fiber reinforced plastics for mass-produced passenger cars. In Proceedings of the 9th Japan International SAMPE Symposium, Tokyo, Japan, 29 November-2 December 2005.

8. Zhang, Y.; Huang, T.; Wang, Y.; Zhang, J.; Wang, J. Environmental assessment of concrete beams strengthened with fibre-reinforced polymer. Proc. Inst. Civ. Eng. Eng. Sustain. 2021, 174, 37-45. [CrossRef]

9. Das, S. Life cycle assessment of carbon fiber-reinforced polymer composites. Int. J. Life Cycle Assess. 2011, 16, 268-282. [CrossRef]

10. Fazio, P. Basalt fiber: From earth an ancient material for innovative and modern application. Energ. Ambientee Innov. 2011, 3, 89-96.

11. Kopietz, M.; Friedrich, K.; Wetzel, B. In situ functionalisation of organomineral hybrid resins for tough basalt fibre reinforced plastics. Plast. Rubber Compos. 2021, 50, 105-115. [CrossRef]

12. Yoder, H.S., Jr.; Tilley, C.E. Origin of basalt magmas: An experimental study of natural and synthetic rock systems. J. Petrol. 1962, 3, 342-532. [CrossRef]

13. Wu, Q.; Xiaoa, S.; Iwashita, K. Experimental study on the interfacial shear stress of RC beams strengthened with prestressed BFRP rod. Results Phys. 2018, 10, 427-433. [CrossRef]

14. Jamshaid, H.; Mishra, R. A green material from rock: Basalt fiber-A review. J. Text. Inst. 2016, 107, 923-937. [CrossRef]

15. Wang, Z.K.; Zhao, X.L.; Xian, G.J.; Wu, G.; Singh Raman, R.K.; Al-Saadi, S. Tensile properties of basalt-fibre reinforced polymer (bfrp) bars within seawater and sea sand concrete environment. In Proceedings of the 7th Conference on Fibre Reinforced Composites, Hong Kong, China, 14-16 December 2016; pp. 791-796.

16. Pavalan, V.; Thauth Himana, I.; Sivagamasundari, R. Study on tensile behaviour of basalt fibre reinforced polymer bars. Int. J. Adv. Technol. Eng. Explor. 2018, 5, 78-82. [CrossRef]

17. Li, Z.; Ma, J.; Ma, H.; Xu, X. Properties and applications of basalt fiber and its composites. Conf. Ser. Earth Environ. Sci. 2018, 186, 012052. [CrossRef]

18. Chen, W.; Hao, H.; Jong, M.; Jian, C.; Shi, Y.; Chen, L.; Pham, T.M. Quasi-static and dynamic tensile properties of basalt fibre reinforced polymer. Compos. Part B Eng. 2017, 125, 123-133. [CrossRef]

19. Hashim, U.R.; Jumahat, A.; Mahmud, J. Improved tensile properties of basalt fibre reinforced polymer composites using silica nanoparticles. Mater. Werkst. 2019, 50, 1149-1155. [CrossRef]

20. Azimpour-Shishevan, F.; Akbulut, H.; Mohtadi-Bonab, M.A. Effect of thermal cycling on mechanical and thermal properties of basalt fibre-reinforced epoxy composites. Bull. Mater. Sci. 2020, 43, 88. [CrossRef]

21. Hu, Y.-J.; Jiang, C.; Liu, W.; Yu, Q.-Q.; Zhou, Y.-L. Degradation of the in-plane shear modulus of structural BFRP laminates due to high temperature. Sensors 2018, 18, 3361. [CrossRef]

22. Lu, Z.; Xian, G. Combined effects of sustained tensile loading and elevated temperatures on the mechanical properties of pultruded BFRP plates. Constr. Build. Mater. 2017, 150, 310-320. [CrossRef]

23. Matykiewicz, D.; Lewandowski, K.; Dudziec, B. Evaluation of thermomechanical properties of epoxy-basalt fibre composites modified with zeolite and silsesquioxane. Compos. Interfaces 2016, 24, 1-10. [CrossRef]

24. Li, Z.-X.; Zhang, X.; Shi, Y. Experimental study on dynamic properties of BFRP laminates used for structural strengthening under high strain rates. Constr. Build. Mater. 2020, 251, 118731. [CrossRef]

25. Michalek, G.; Rehbein, J. Biresin CR144 Statement of Approval: WP 1520029HH; Sika Deutschland GmbH: Hamburg, Germany, 2015.

26. Sober, D.J. Core-Shell Toughening Systems for Thermosetting Resins; Kaneka Texas Corporation: Houston, TX, USA, 2007.

27. Ehrenstein, G.W. Faserverbund-Kunststoffe: Werkstoffe-Verarbeitung_Eigenschaften, 2 Völlig Überarbeitete Auflage; Carl Hanser Verlag GmbH \& Co. KG: München, Germany, 2006; ISBN 9783446457546.

28. Deutsches Institut für Normung. EN 2561: Carbon Fibre Reinforced Plastics-Unidirectional Laminates, Tensile Test Parallel to the Fibre Direction; Beuth Verlag GmbH: Berlin, Germany, 1995.

29. DIN Deutsches Institut für Normung. Metallic Materials_Verification of Static Uniaxial Testing Machines: Part 1: Tension/Compression Testing Machines-Verification and Calibration of the Force-Measuring System; Beuth Verlag GmbH: Berlin, Germany, 2004.

30. Deutsches Institut für Normung. EN 2565: Preparation of Carbon Fibre Reinforced Resin Panels for Test Purposes; Beuth Verlag GmbH: Berlin, Germany, 2013.

31. Frick, A.; Stern, C. Einführung in Die Kunststoffprüfung: Prüfmethoden und Anwendungen; Hanser: München, Germany, 2017; ISBN 9783446449886.

32. DIN Deutsches Institut für Normung. Products and Systems for the Protection and Repair of Concrete Structures-Test MethodsDetermination of Glass Transition Temperatures of Polymers: EN 12614:2004; Beuth Verlag GmbH: Berlin, Germany, 2005.

33. Aleksandrov, V.A.; Penkina, N.A.; Ustinova, T.P.; Vlaznev, D.P. Effect of heat-treated basalt fibre on the structure of chemisorption composite material made from it. Fibre Chem. 2008, 40, 496-498. [CrossRef]

34. Fiore, V.; Scalici, T.; Di Bella, G.; Valenza, A. A review on basalt fibre and its composites. Compos. Part B Eng. 2015, 74, 74-94. [CrossRef]

35. Amuthakkannan, P.; Manikandan, V.; Winowlin Jappes, J.T.; Uthayakumar, M. Effect of fibre length and fibre content on mechanical properties of short basalt fibre reinforced polymer matrix composites. Mater. Phys. Mech. 2013, 16, 107-117. 
36. Weichand, P.; Gadow, R. Basalt fibre reinforced SiOC-matrix composites: Manufacturing technologies and characterisation. J. Eur. Ceram. Soc. 2015, 35, 4025-4030. [CrossRef]

37. Colombo, C.; Vergani, L.; Burman, M. Static and fatigue characterisation of new basalt fibre reinforced composites. Compos. Struct. 2012, 94, 1165-1174. [CrossRef]

38. Subagia, I.A.; Kim, Y.; Tijing, L.D.; Kim, C.S.; Shon, H.K. Effect of stacking sequence on the flexural properties of hybridcomposites reinforced with carbon and basalt fibers. Compos. Part B Eng. 2014, 58, 251-258. [CrossRef]

39. Nizic, A. Low Cycle Fatigue of the Bond of Externally Bonded Reinforcement. Ph.D. Thesis, Technische Universität München, Munich, Germany, 2011.

40. Shi, J.; Chen, Z.; Shao, S.; Zheng, J. Experimental and numerical study on effective thermal conductivity of novel form-stable basalt fiber composite concrete with PCMs for thermal storage. Appl. Therm. Eng. 2014, 66, 156-161. [CrossRef]

41. Narayanan, A.; Shanmugasundaram, P. Evaluation of heat resisting behaviour of basalt fibre reinforced FG tiles. Constr. Build. Mater. 2018, 170, 679-689. [CrossRef]

42. Manoharan, S.; Shihab, A.I.; Alemdar, A.S.A.; Babu, L.G.; Vijay, R.; Lenin Singaravelu, D. Influence of recycled basalt-aramid fibres integration on the mechanical and thermal properties of brake friction composites. Mater. Res. Express 2019, 6, 115310. [CrossRef]

43. Yang, S.-Y.; Ma, C.-C.M.; Teng, C.-C.; Huang, Y.-W.; Liao, S.-H.; Huang, Y.-L.; Tien, H.-W.; Lee, T.-M.; Chiou, K.-C. Effect of functionalized carbon nanotubes on the thermal conductivity of epoxy composites. Carbon 2010, 48, 592-603. [CrossRef]

44. Hussein, S.I.; Abd-Elnaiem, A.M.; Asafa, T.B.; Jaafar, H.I. Effect of incorporation of conductive fillers on mechanical properties and thermal conductivity of epoxy resin composite. Appl. Phys. A 2018, 124, 475. [CrossRef]

45. Goldstein, J.I.; Newbury, D.E.; Michael, J.R.; Ritchie, N.W.; Scott, J.H.J.; Joy, D.C. Scanning Electron Microscopy and X-ray Microanalysis, 4th ed.; Springer: New York, NY, USA, 2018.

46. Schmitt, A.; Carvelli, V.; Haffke, M.M.; Pahn, M. Thermo-mechanical response of concrete sandwich panels reinforced with glass fiber reinforced polymer bars. Struct. Concr. 2018, 19, 839-850. [CrossRef]

47. Bies, N.S.; Keller, M.L.; Pahn, M. Characterisation of the degradation behaviour of a loaded vinyl ester GFRP bar in alkaline concrete environment. In Proceedings of the 10th International Conference on FRP Composites in Civil Engineering, Istanbul, Turkey, 8-10 December 2021; Ilki, A., Ispir, M., Inci, P., Eds.; Springer International Publishing: Cham, Switzerland; pp. 714-725.

48. Keller, M.L.; Pahn, M.; Kopietz, M.; Wetzel, B. Long-term-performance of Loaded GFRP Bars in Alkaline Environment. In Proceedings of the 8th Biennial Conference on Advanced Composites in Construction (ACIC-17), Sheffield, UK, 5-7 September 2017; pp. 97-102. 